\title{
El uso de la imagen digital en el diseño y el desconocimiento sobre aspectos legales relacionados a la materia en estudiantes de la carrera
}

\begin{abstract}
Descripción de la realidad problemática. Hoy en día,se puede decir que desde que uno se levanta hasta que se acuesta, vive rodeado de anuncios publicitarios; hace unos años atrás se calculaba que una persona recibía 3000 publicidades diariamente. Regueira (2016), menciona que son 5000 impactos publicitarios aproximadamente que una persona recibe por día. Información que no solo destaca por la exorbitante cifra, sino también por la ascendente cantidad de anuncios que en los últimos años se están incorporando a la vida cotidiana.Y es que internet, siendo un medio ineludible para la publicidad, es parte de este acelerado crecimiento.
\end{abstract}

La evolución de los medios y la aparición de nuevos soportes digitales es un hecho. Asimismo, las formas de obtener imágenes y recursos visuales en internet para fines gráficos publicitarios han ido de la mano con este crecimiento y son mucho más diversas e inmediatas; $\sin$ embargo, también negligentes e informales. Parte de la realidad peruana es ser un país donde la informalidad es un fenómeno casi omnipresente, no solo en comercios de ropa, calzado, piratería de libros, películas y música; sino también en el ámbito del diseño gráfico, la fotografía y la publicidad.

Loayza (2008), define que el pertenecer al sector informal supone estar al margen de las cargas tributarias y normas

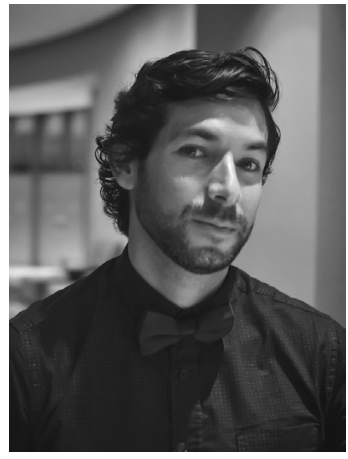

Mtro. Christopher Carrasco Saavedra Universidad San Ignacion de Loyola www.chriscarrasco.net Lima, Perú. 
legales. En el diseño publicitario, esto sucede cuando se viola el derecho de autor, se pasa por alto el derecho de imagen y no se respetan las licencias ni el uso de obras intelectuales de terceros.

Casos reales de esta problemática en nuestro país han sido titulares en diversos medios informativos, causando consecuencias negativas, perjudicando el prestigio y la imagen de marcas reconocidas, como por ejemplo:

Caso Topitop, tienda de ropa que fue acusada por el artista australiano Jeremyville por plagiar diseños suyos y aplicarlo en polos con la marca de la tienda. (Diario Gestión, 2013).

Caso América Televisión, reality de concurso juvenil, "Esto es Guerra", usó imágenes cuyos derechos de autor no le pertenecen, para utilizarlos como logotipos en los dos equipos que forman parte del programa. (Diario La República,2014).

Caso álbum del Mundial Rusia 2018 “3 Reyes”, INDECOPI podría multar hasta con S/ 747.000 (180 UIT) contra las empresas que comercializaron los stickers, ya que las fotografias incluidas en las figuritas están protegidas por la legislación sobre derecho de autor, y para que puedan ser utilizadas se requiere de la autorización correspondiente de los titulares de los derechos, lo cual no habría ocurrido. (Diario El Comercio, 2018).

Caso Euroshop con la marcaVolkswagen, donde se ve claramente cómo la fotografía de un perro producida para campaña publicitaria de Panasonic en Australia, es desvergonzadamente reutilizada por un diseñador de la concesionaria de carros en Perú para una publicidad por Facebook deVolkswagen. (Blog de marketing,publicidad y diseño de Joe La Pompe, 2018).

Estos son solo una pequeña muestra del gran número de casos que se presentan día a día en nuestro país respecto a infracciones relacionadas a la propiedad intelectual, el diseño y la publicidad.

Es así como surgen preguntas no solo de valor ético, sino incluso de aspectos legales, ¿unas simples disculpas solucionan el problema?, ¿cuántos casos como este sucederán día a día?, ¿un diseñador puede hacer uso de cualquier imagen que encuentre en internet?, ¿dónde quedan los derechos de autor?, ¿existen sanciones por la falta de ética profesional? Todas estas interrogantes posiblemente pueden explicarse por la falta de información en los diseñadores gráficos sobre temas legales relacionados a la publicidad y a la utilización de imágenes, fotografias o recursos visuales en la red. Responsabilidad que, inevitablemente se encuentra vinculada a las escuelas, institutos y universidades de dicho rubro profesional.Es en este contexto, que la formación e información sobre legislación relacionada al diseño y la publicidad queda en la mayoría de casos relegada en las mallas curriculares de las carreras de diseño gráfico publicitario.

El Perú ya está inmerso en esta gran ola que es la era digital, el internet no solo es uno de los medios de comunicación más utilizados, sino también una herramienta y un medio casi indispensable para los sectores creativos. Sin embargo, ¿cómo está relacionado el internet y el diseño publicitario con la informalidad en el uso de imágenes?, ¿Cuántos de los aproximadamente 5000 anuncios que recibe una persona serán obras originales y cuántos estarán infringiendo alguna norma legal? Aunque no exista una respuesta exacta para esta última pregunta, si existe un problema implícito que muchas veces es dejado de lado y que es un tema que merece ser estudiado por cuestiones éticas y legales por respeto hacia el trabajo de terceros. Por tal motivo, mediante la presente investigación, se desea analizar y determinar la relación que existe entre la utilización de imágenes de internet y el desconocimiento por parte de diseñadores gráficos publicitarios sobre aspectos legales relacionados al ámbito creativo.

Justificación de la investigación. La presente investigación busca afectar positivamente aspectos de índole profesional, pedagógico y de realidad social en la industria gráfica. Como profesional licenciado en diseño y magíster en publicidad, considero que existe una habitual carencia de información en diseñadores sobre temas de legislación publicitaria, lo cual es de suma importancia para el desarrollo responsable de esta profesión. En el aspecto pedagógico, como docente universitario, considero relevante que se conozca esta información por los beneficios que aportaría a las nuevas generaciones de estudiantes de diseño gráfico y publicidad al saber hacer un uso apropiado de los recursos visuales y/o creaciones bajo los requerimientos legales respectivos, trayendo en sí una consecuencia positiva para ellos al poder reducir los errores y faltas que puedan cometer profesionalmente en el campo laboral. 
-Justificación teórica: Esclarecimiento y profundización sobre temas legislativos relacionados a la publicidad y a la utilización correcta de las imágenes en internet. Reforzar la importancia por el respeto hacia el derecho de autory reafirmar puntos importantes sobre la ética publicitaria y sus regulaciones. Aporte teórico hacia la comunidad de profesionales en diseño gráfico, publicidad y comunicaciones, así como también a estudiantes en pregrado de universidades de Lima. Analizar los conocimientos e información que se tiene sobre dichos temas y considerar su incorporación e importancia como contenidos en mallas curriculares en carreras de diseño y publicidad.

-Justificación práctica: La elección de los centros de estudio como muestra de la investigación se debe a su relevancia social para el ámbito del diseño y la publicidad en Lima. Según ranking publicado por el diario Gestión (2017) y elaborado por el Ministerio de Trabajo, los egresados de la Universidad "A" son quienes tienen la mejor remuneración promedio como universidad en la carrera de diseño. Mientras que la relevancia de Universidad "B" radica por ser considerada como la única universidad especializada en carreras creativas en el Perú, la cual está teniendo un notable crecimiento.

Metodología. El diseño de la investigación es no experimental.Tiene el fin de responder a los problemas del estudio y contrastar las hipótesis planteadas. Se realizó sin manipular alguna de las variables, ya que los efectos generados entre ellas, existen. En otras palabras, consiste en observar el problema de la misma manera como se da en la realidad, para después comprobarse. La investigación es de corte transversal simple porque se aplicará el instrumento en una sola ocasión; y tiene un enfoque cuantitativo.

Diseño muestral. Conformado por estudiantes de diseño gráfico publicitario de dos universidades de Lima durante el ciclo 2018-1. Universidad " $A$ " (total alumnos de la carrera: 472, total último año: 213); y Universidad "B" (total alumnos de la carrera: 359, total último año: 37). Universo poblacional: 831 alumnos.Total de alumnos en último año de carrera de las dos universidades: 250 . Para trabajar la muestra, se ha considerado a los alumnos del último año de la carrera (9no y $10 \mathrm{mo}$ ciclo) de diseño gráfico publicitario por lo que son los más cercanos a egresar y desempeñarse en el ámbito laboral.

- Muestra Universidad “A":50 encuestados.

- Muestra Universidad "B":37 encuestados.
Aplicación y resultados. El cuestionario estuvo conformado por 30 preguntas, en su mayoría cerradas dicotómicas y con opciones múltiples para un análisis de resultados más preciso; también hubieron preguntas abiertas con el fin de conseguir información más específica sobre el nombre de cursos de legislación y ética publicitaria que llevan los estudiantes, y los medios utilizados para obtener y vender imágenes digitales en internet. Con dicho instrumento se buscó demostrar el nivel de conocimiento que estudiantes del último año de carrera tienen sobre aspectos legales relacionados al diseño y a la publicidad.

En base a la información obtenida en los resultados de la encuesta, se puede percibir cierta similitud en los porcentajes y datos recibidos en las respuestas de ambas universidades, validando que el problema planteado inicialmente no es específicamente de una sola institución si no es un problema general que pertenece a la realidad actual de la industria del diseño y la publicidad en el Perú.

En ambas universidades el medio más utilizados para obtener imágenes son los buscadores web (con un promedio de 71\%), información que es relevante para el estudio ya que estos medios solo buscan y filtran las imágenes en la web, mas no tienen la opción de adquirir alguna licencia para su uso. El buscador web más usado para descargar imágenes y aplicarlas en proyectos gráficos publicitarios es Google, seguido porYahoo y finalmente Bing.

Con respecto a las redes sociales, el 32\% de "A" y el $37.8 \%$ de "B" afirman utilizarlas para obtener imágenes. En promedio de las dos universidades, la red social más usada para descargar imágenes y aplicarlas en proyectos gráficos publicitarios es Pinterest con 68\%, luego Facebook con $53 \%$, Flickr con $43 \%$ e Instagram con $40 \%$.De los 87 casos, hubo un estudiante que escribió como otra alternativa la red social "Unsplash", lo cual ha sido un aporte positivo para la investigación ya que indagando sobre esta plataforma, es una red social de fotógrafos en la que éstos a modo de comunidad comparten sus imágenes con la opción de descargarlas y cumpliendo la funcionalidad de un banco de imágenes gratuito; a diferencia de las demás redes sociales que no están diseñadas para adquirir alguna licencia de uso de las fotografias o ilustraciones que encuentren, lo cual permite concluir que un gran porcentaje de estudiantes suele descargar y usar imágenes de redes sociales sin licencia alguna o permiso del autor. 
En cuanto a los bancos de imágenes, el 21.6\% de alumnos de "B" afirma haber pagado por adquirir alguna foto o vector a través de estos medios, mientras que en " $\mathrm{A}$ " el 24\%.Por otro lado, tan solo el 5.4\% de "B"y el 6\% de "A" ha subido y vendido una imagen por internet, porcentajes similares que representan una notable minoría. Dentro de los tipos de imágenes digitales que más descargan en internet, las fotografias (77\%) son las más utilizadas; luego los vectores (60\%), los mockups (31\%) y los videos (2\%).

Sobre la pregunta, ¿Alguna vez han descargado una foto o vector de internet sin la autorización del autor de la obra y la han utilizado para un proyecto gráfico publicitario real?,"B" tuvo un porcentaje mayor que "A", con 43.2\% sobre $34 \%$, sin embargo, ambas datos son significativos para afirmar que más de un tercio de los encuestados ha infringido el derecho de autor a través de internet.

Más del 70\% de estudiantes de ambas universidades se encuentran trabajando. Por tal motivo, es importante conocer y establecer los parámetros específicos al momento de obtener o vender una imagen por internet, ya que existe un riesgo y una responsabilidad al reproducir la foto o ilustración si es que dichos acuerdos no están claros.

En lo que respecta al ámbito legal, el 86\% de ambas universidades declaran no haber llevado algún curso que aborde temas sobre legislación publicitaria o derecho aplicado en el diseño. En respuesta a esto, el 95\% de encuestados consideran que en una carrera de pregrado de diseño sería importante que se toquen temas de legislación publicitaria, ya que para el 92\% de ellos es muy importante conocer sobre estos temas para realizar campañas gráficas publicitarias.

Aproximadamente el $66 \%$ de la muestra conoce entre poco y nada sobre la Ley del Derecho de Autor, en cuanto a la Propiedad Industrial solo el 8\% conoce lo necesario, el $53 \%$ conoce entre poco y nada sobre el Derecho de Imagen, el 70\% dice conocer entre poco y nada sobre los tipos de licencias de uso en imágenes de internet y solo el $1 \%$ que representa a un alumno dice conocer mucho al respecto.

El 83\% de los estudiantes encuestados confirman nunca leer las condiciones y licencias de uso cuando descargan imágenes o vectores gratuitos, lo cual es un indicador alarmante sobre la falta de importancia que se le da al reconocimiento del trabajo de terceros, obviando y po- siblemente infringiendo ciertas condiciones de uso para las imágenes descargadas, como por ejemplo que algunas son solo para uso personal mas no comercial o que es obligatorio mencionar los créditos del autor donde sea utilizada la foto o el vector, entre otras condiciones. El 92\% conoce entre poco y nada sobre las licencias Creative Commons. Sobre éstas últimas sería importante para ellos conocer al respecto, ya que dentro de sus diversos tipos de licencia hay unas que permiten un libre uso de las imágenes para proyectos gráficos y publicitarios, personales y comerciales.

Por último, se puede observar que hay también un gran porcentaje de alumnos que no conocen sobre las sanciones y penas por infringir el derecho de autor $(88 \%$ afirma conocer entre poco y nada).Y el $92 \%$ no conoce los mecanismos de solución o procedimientos para denunciar en caso que alguien utilice una fotografía o diseño suyo.

\section{Conclusiones.}

-Primera: Hay un gran desconocimiento sobre temas legales relacionados al diseño y la publicidad en alumnos de ambas universidades, lo cual trae como consecuencia que jóvenes diseñadores usen las imágenes digitales de internet obviando los derechos de autor de terceros y aplicándolas en campañas o proyectos gráficos publicitarios con clientes reales.

-Segunda: Si se utilizan los buscadores web o las redes sociales para descargar imágenes sin comunicación previa con el autor o con la persona que figura en la fotografia, es probable que no se esté respetando la propiedad intelectual o el derecho de imagen. Mientras que si se utiliza bancos de imágenes para el mismo fin, existe una garantía en que esas imágenes hayan pasado por un proceso de validación y legalmente puedan ser utilizadas.

-Tercera: Mediante el estudio de campo y el trabajo estadístico se pudo validar y demostrar que mientras los estudiantes no conozcan aspectos éticos profesionales de la carrera y no sepan sobre las posibles sanciones, penas, o procedimientos a seguir por violar la propiedad intelectual de terceros, difícilmente el panorama sea perfecto respecto en la distribución de imágenes, ya que entre los usuarios de estas existirá aún mucha informalidad.

\section{Recomendaciones.}

-Primera: Incluir en las mallas curriculares de carreras de diseño gráfico, diseño publicitario o diseño empresarial 
de pregrado, contenidos sobre legislación publicitaria y ética profesional aplicada a la especialidad.

-Segunda: Para obtener imágenes de internet y usarlas en proyectos gráficos publicitarios no se recomienda descargarlas directamente de buscadores web o redes sociales, ya que por lo general éstas no cuentan con una cesión de derechos para usos de la obra, lo cual puede traer problemas legales futuros. Se recomienda utilizar bancos de imágenes ya que en ellos las licencias se encuentran tipificadas y estandarizadas. De no contar con un presupuesto para pagar por una licencia, se recomienda hacer uso de bancos de imágenes gratuitos como Pixabay, Unsplash, Pexels, entre otros, en los que las imágenes son de alta calidad y cuentan con licencias de libre uso.

-Tercera: Enseñar a alumnos a vender fotos, vectores o ilustraciones a través de bancos de imágenes, de esa manera conocerán y entenderán mejor sobre las licencias de uso de imágenes en internet, podrán tener ingresos económicos extras y aprenderán a valorar y respetar el derecho de autor.

-Cuarta: Dar a conocer las sanciones, penas y procedimientos de denuncia en casos de infracción por violación a la propiedad intelectual o plagio, para que los actuales y los futuros profesionales puedan hacer valer sus derechos como artistas, fotógrafos, publicistas o diseñadores; y sean conscientes de la gran repercusión y responsabilidad que tienen al trabajar con la imagen de marcas, empresas o con la imagen de uno mismo como profesional. 